\title{
Pleomorphic Adenoma of the Nasal Cavity
}

\author{
Tolga Kandoğan, Abdullah Dalğıç', Gürol Gültekin1, Seçkin Ulusoy², Elif Selek \\ ${ }^{1}$ Clinic of Otolaryngology, İzmir Bozyaka Training and Research Hospital, İzmir, Turkey \\ ${ }^{2}$ Clinic of Pathology, İzmir Bozyaka Training and Research Hospital, Izmir, Turkey \\ ${ }^{3}$ Clinic of Otolaryngology, Gaziosmanpaşa Taksim Training and Research Hospital, İstanbul, Turkey
}

\begin{abstract}
Pleomorphic adenoma is mixed and usually benign tumor originating salivary glands. The most common salivary gland tumor is pleomorphic adenoma. The most common localization of pleomorphic adenoma is parotid gland. Although it is found in major salivary gland, pleomorphic adenoma may be found paranasal sinuses and nasal cavity rarely. A 74-year-old female presented with a 3-month history of right-sided nasal obstruction was presented. Although it is infrequently, the possibility of pleomorphic adenoma should be kept in mind while assessing well-defined lobular intranasal lesions. (JAREM 2015; 5: 25-7)
\end{abstract}

Keywords: Adenoma, pleomorphic adenoma, nasal cavity

\section{INTRODUCTION}

Pleomorphic adenoma (PA) is a mixed, usually benign tumor of the main salivary glands, mostly observed in the parotid gland (1). Although few cases have been reported in other sites, PA of the nasal cavity is still rarely observed (2). There is no consensus about the origin of the PA tumors in the nasal cavity. Only a few reports have documented the presence of this tumor along the nasal septum exist (2). For most patients, the chief complaint is a unilateral nasal obstruction and/or occasional epistaxis (3). Here we present an intranasal PA located on the septum nasi.

\section{CASE PRESENTATION}

A 74-year-old female presented with a 3-month history of right-sided nasal obstruction. She had no previous history of nasal polyposis. Questioning about the complaints revealed that she had epistaxis a few times previously. Anterior rhinoscopy and endoscopy revealed a mucosa-covered polypoidal mass obstructing the right nasal cavity, possibly originating from the nasal septum. The mass was friable and bled easily when touched with an instrument. CT showed a unilateral right-sided soft tissue mass, expanding from the septum to the lateral wall. Paranasal sinuses were normal with no signs of infection or polyposis (Figure 1). Instead of performing a biopsy, we planned a complete removal of the mass with endoscopic surgery. The tumor was completely removed.

The tumor was pedunculated on the cartilaginous nasal septum. The overall postoperative histology was PA with a marked myoepithelial component (Figure 2, 3). The postoperative course was uneventful, and the patient was discharged. Written informed consent was obtained from the patient who participated in this study.

\section{DISCUSSION}

Pleomorphic adenoma is an encountered pathology in the major salivary glands tumors. It is less frequent in minor salivary glands of the hard and soft palates (4). Other rare sites are the upper aerodigestive tract, including the nasal cavity, pharynx, larynx, trachea, and lacrimal glands (4). The majority of intranasal PAs arise from the nasal septum. PAs originating from the lateral wall and inferior turbinate account for $9.8 \%-20 \%$ of the reported cases, although most of the minor mucous and serous glands are located in the lateral nasal wall and turbinates (1-3). PA of the nasal cavity is more frequently observed in women and between the third and sixth decades of life (4). Most symptoms are nasal obstruction, epistaxis, and intermittent nasal discharge. The tumor size varies from $5 \mathrm{~mm}$ to $7 \mathrm{~cm}$ (4). PAs are dome-shaped, exophytic, polypoid, oval, firm, gray, smooth, and with capsule. No destruction of the surrounding tissue is observed (5).

On CT images, these tumors show a well-defined, homogenous, soft tissue mass with smooth remodeling of the surrounding bones. Calcification is rare (3). It is think benign and malign tumors in the differential diagnosis of the nasal septum mass such as sinonasal polyposis, inverted papilloma, juvenile angiofibroma squamous cell carcinoma, chondrosarcoma, adenocarcinoma, sinonasal melanoma, and benign minor salivary gland tumor (4).

Malignant transformation of PA of the nasal cavity has been reported in $2.4 \%-10 \%$ of cases (6). Although it is reported that PAs arising from the nasal septum are usually multilobulated and calcificated on CT, in our case, the mass was solid and homogenous without any signs of lobulations and calcifications. 


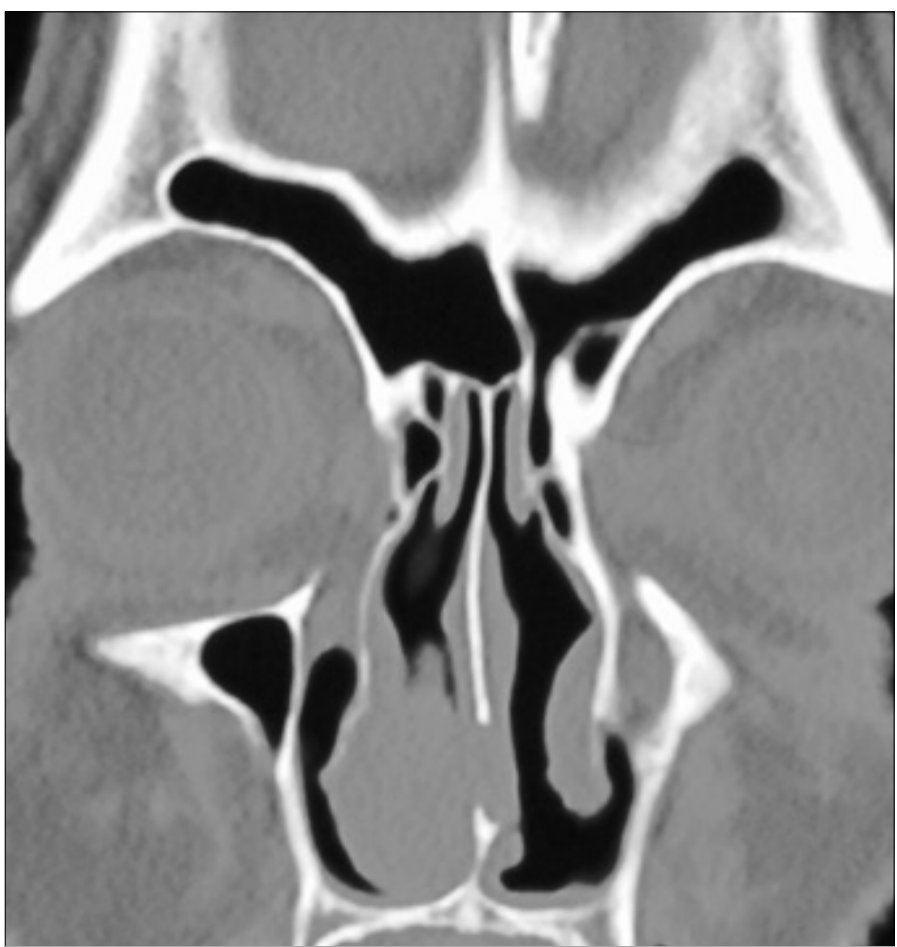

Figure 1. Paranasal sinuses are normal, with no signs of infection or polyposis in the paranasal CT CT: computed tomography

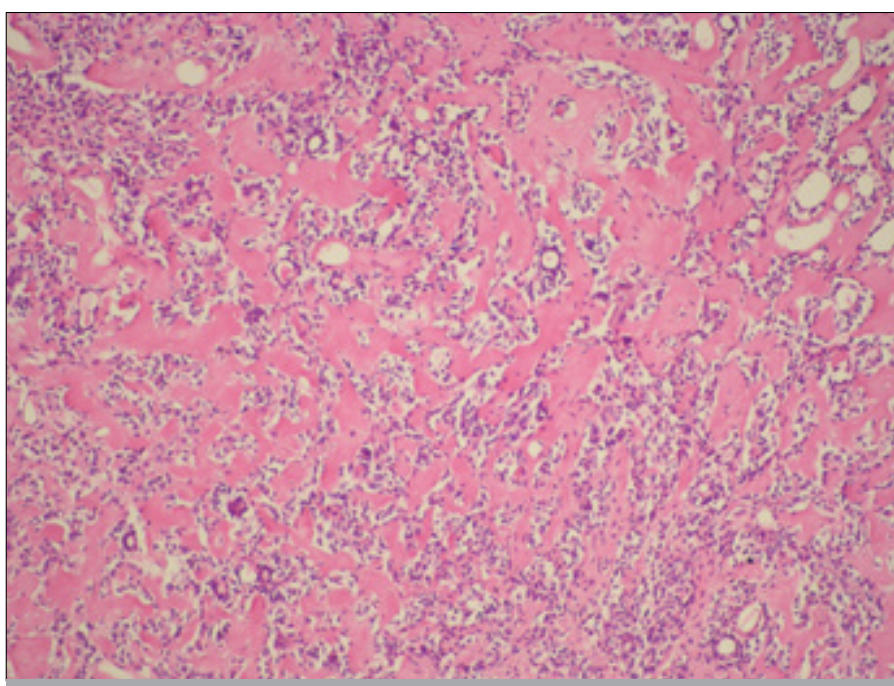

Figure 2. Epithelial component embedded with hyalinized stromal area under a light microscope

Intranasal mixed tumors have a relatively low rate of recurrence $(10 \%)$, in comparison with the high rate of recurrence $(50 \%)$ in parotid gland mixed tumors and $25 \%$ for intra-oral mixed tumors. This is because of the very cellular pattern with few areas of stromal predominance in mixed salivary tumors of the nasal fossa (7). Surgical excision with clear margins is the treatment of choice for PA, irrespective of the site of origin. Approaches depend on the size and location and include lateral rhinotomy, intranasal excision, or midfacial degloving (3).

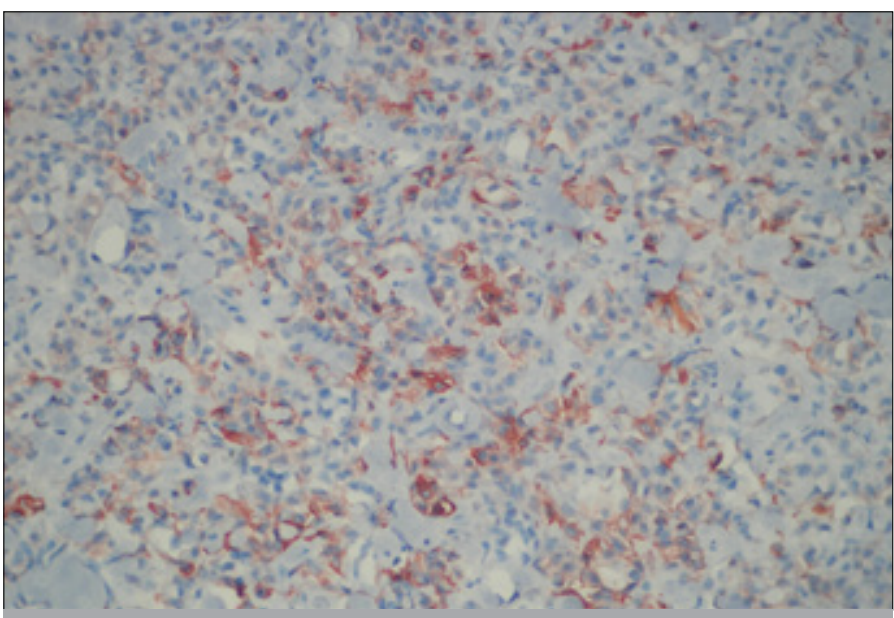

Figure 3. Actine positivity in myoepithelial cells (Actinex 200)

If these neoplasms are allowed to progress untreated, their expansion may cause local destruction of the paranasal sinuses (5). Nevertheless, postoperative follow-up is necessary for all patients with intranasal PA because as many as $10 \%$ of patients may experience a recurrence despite wide local excision with clear margins (5).

\section{CONCLUSION}

Pleomorphic adenomas of the nasal cavity are rare neoplasms that are difficult to diagnose. In addition, it should be kept in mind that although recurrence and metastasis are uncommon, patients need to be followed postoperatively.

Informed Consent: Written informed consent was obtained from patient who participated in this study.

Peer-review: Externally peer-reviewed.

Author contributions: Concept - T.K.; Design - A.D., T.K.,G.G.; Supervision - T.K.; Resource - T.K., A.D.; Materials - T.K., G.G., E.S.; Data Collection and/or Processing - T.K., G.G.; Analysis and/or Interpretation - T.K., A.D., E.S.; Literature Search - A.D., S.U.; Writing - T.K., A.D., S.U.; Critical Reviews - T.K., A.D., G.G.; Other - S.U., E.S.

Conflict of Interest: No conflict of interest was declared by the authors.

Financial Disclosure: The authors declared that this study has received no financial support.

\section{REFERENCES}

1. Yazibene $Y$, Ait-Mesbah N, Kalafate S, Yahi-Ait Mesbah N, Abdennebi $A$, Bouzid $H$, et al. Degenerative pleomorphic adenoma of the nasal cavity. Eur Ann Otorhinolaryngol Head Neck Dis 2011; 128: 37 40. [CrossRef]

2. Malinvaud D, Couloigner V, Badoual C, Halimi P, et al. Pleomorphic adenoma of the nasal septum and its relationship with Epstein-Barr virus. Auris Nasus Larynx 2006; 33: 417-21. [CrossRef]

3. Fushiki $\mathrm{H}$, Morijiri M, Maruyama M, Motoshima $\mathrm{H}$, Watanabe $\mathrm{Y}$. MRI of intranasal pleomorphic adenoma. Acta Otolaryngol 2006; 126: 889-91. [CrossRef]

4. Oztürk E, Sağlam O, Sönmez G, Cüce F, Haholu A. CT and MRI of an unusual intranasal mass: pleomorphic adenoma. Diagn Interv Radiol 2008; 14: 186-8.

5. Acevedo JL, Nolan J, Markwell JK, Thompson D. Pleomorphic adenoma of the nasal cavity: a case report. Ear Nose Throat J 2010; 89: 224-6. 
6. Kumagai M, Endo S, Koizumi F, Kida A, Yamamoto M. A case of pleomorphic adenoma of the nasal septum. Auris Nasus Larynx 2004; 31: 439-42. [CrossRef]
7. Compango J, Wong RT. Intranasal mixed tumours (pleomorphic adenoma): A clinical pathological study of 40 cases. Am J Clin Pathol 1977; 68: 213-8. 